\title{
Competitive horizons
}

Robust growth predicted for textiles and clothing sector in Vietnam

\section{UK food and drink industry set to prosper}

\section{Report indicates considerable scope for mobile advertising}

According to a report from business information company Textiles Intelligence, the textile and clothing industry in Vietnam is set for a period of high growth. The report, as published by www.innovationintextiles.com, claims that production will increase by an average of between 12-14 per cent through to the end of the current decade. By that time, it is also predicted that exports will rise from US\$28bn in 2016 to US\$50bn. This represents growth of 15 per cent. Scope exists to expand Vietnam's domestic market, where urbanization and disposable income are on the increase. The young age profile of consumers is another important characteristic as is the fact that their spending on clothing is second only to food purchases. However, Textiles Intelligence believes that certain changes are needed for this level of growth to occur. Firms are urged to become original design manufacturers (ODMs) and deal more directly with foreign customers instead of mostly filling the subcontractor role. In addition, production should considerably increase its use of fabric produced in Vietnam. A shift toward manufacturing more high-end fashion items is also recommended. Production in the sector will further benefit from improvements in research, training, and development, the report claims. Greater competency in marketing and distribution is likewise needed.

Worldwide demand for produce manufactured in the UK is set to further strengthen growth in the country's food and drink sector. Industry exports have risen sharply in recent years and their value reached a new high of over £20bn in 2016. Extensive scope exists to increase exports even more as only one in five UK food and drink manufacturers currently operates in overseas markets. Europe accounts for 60 per cent of all exports, and optimism remains high despite uncertainties associated with Brexit. However, the last two decades have witnessed strongest export growth in the Americas and Asia and Oceania. Demand for UK food and drink products has also risen sharply in Africa and the Middle East, although this region is only responsible for 8 per cent of total industry exports. A report by Santander and manufacturers' organization EEF claims that future potential will also be driven by the introduction of automation and other new technologies to enhance production processes. An increased emphasis on healthier foods is regarded as significant too. As published by www.themanufacturer.com, the report points out that future expansion of the UK food and drink sector will additionally benefit from increased innovation, growth in online shopping, and the introduction of smart packaging and greater sustainability.

A global survey conducted by the Internet Advertising Bureau (IAB) has found similarities in smartphone usage among consumers all over the world. A high percentage of users access the internet one or more times a day either via mobile apps or mobile Web. As reported by www.thedrum.com, the survey focused on numerous markets across five continents and revealed that digital advertising is making a significant impact on consumers. Recall of ads viewed on mobile devices was 86 per cent via mobile Web and 90 per cent from apps. Almost half of mobile users surveyed admitted to responding to such ads whichever way they were viewed. According to IAB, the high level of user awareness suggests that significant opportunities might exist for mobile marketers.

The International Monetary Fund (IMF) expects the economy in China to expand by 6.7 per cent during 2017, a report published by www.chinapost.com points out. The report also notes that China has the capacity to grow by an annual average of 6.4 per cent through to 2020 end. However, the IMF believes that sustaining consistent growth over the medium term needs the country to move away from an economic model based on credit-fuelled investment and debt. A swifter transition to more reliance on consumption rather than investment is one recommendation by the global organization. The Chinese economy would also receive a boost, if market forces are afforded a more prominent role and rising debt in the non-financial sector is addressed. Additional suggestions include moves to reduce overcapacity in sectors like coal and steel, along with an overhaul of loss-making state-run enterprises. 